\title{
Variability and predictability of West African monsoon on seasonal and decadal scales
}

\author{
Yongkang Xue ${ }^{1} \cdot$ Serge Janicot $^{2} \cdot$ William K.-M. Lau ${ }^{3}$
}

Published online: 26 November 2016

(C) Springer-Verlag Berlin Heidelberg 2016

Recent observational evidence supports the notion that there are strong decadal climate variabilities in the Sahel and surrounding areas from the 1950 s to the 2000 s, not only in precipitation, but also in sea surface temperature (SST), vegetation cover, land use and land cover change (LULCC), and aerosol loading and spatial distributions (Xue et al. 2016; Boone et al. 2016; Gu et al. 2016). In the 2010 Climate Dynamics Special Issue "West African Monsoon and its Modeling," the skills of general circulation models (GCMs) and regional climate models (RCMs) in properly simulating the West African monsoon (WAM) were extensively evaluated, and possible causes that contribute to model deficiencies were investigated. While these studies provided basic understanding of the seasonal variations of WAM climatology, understanding of the complex interactions of WAM variability associated with SST, land surface, and aerosol forcings at different scales, particularly with respect to seasonal to decadal scale forcing, is still lacking.

This special issue "Decadal variability of the West African monsoon, external surface forcings, and their modeling" aims to provide the latest research on the main WAM dynamic and physical processes, model predictability, and possible interactions between the WAM and external forcings at seasonal to decadal scales. The main themes of this

Yongkang Xue

yxue@geog.ucla.edu

1 Department of Geography, Department of Atmospheric and Oceanic Sciences, University of California, Los Angeles, CA, USA

2 Laboratoire Atmosphères Milieux Observations Spatiales, Sorbonne-Universités, CNRS-UVSQ-UPMC, Paris, France

3 Earth System Science Interdisciplinary Center, Joint Global Change Research Institute, University of Maryland, College Park, MD, USA special issue are: (1) intercomparison and evaluation of skills of GCMs and RCMs in simulating seasonal and decadal variability of WAM rainfall and relevant processes, and its association with SST, LULCC, and aerosol processes, as well as identification of major challenges, deficiencies, and uncertainties that remain in modeling WAM variability; (2) representations of major WAM characteristics and possible underlying physical and dynamic mechanisms; (3) application of observational and reanalyses data as a pathway for model physics evaluation and improvement, and in understanding the WAM variability; and (4) evaluation of RCM downscaling ability in terms of WAM decadal variability. The papers in the special issue are mainly based on research conducted in conjunction with the second phase of the international West African Monsoon Modeling and Evaluation (WAMME II) project and the African Multidisciplinary Monsoon Analysis (AMMA) project.

Most papers in this issue are from the WAMME II project focusing on the interactions between the WAM and external forcings. In the WAMME II experiment, realistic but idealized forcings (setting to maximum forcing amplitude) are imposed to examine WAM responses in the WAMME II models. Among them, Xue et al. (2016) investigate relative effects of the global and several major individual ocean basins on the WAM decadal variability and compare the SST's role and the LULCC effect in initiating and modulating the decadal WAM variability and the 1980s Sahel drought. Boone et al. (2016) use recently available LULCC data to evaluate the sensitivity of WAM seasonal variability to land surface processes and physical mechanisms involved. In addition to multi-model experiments, some of the individual models' results are also presented. Using the aerosol data from the Goddard Chemistry Aerosol Radiation and Transport (GOCART) model, Gu et al. (2016) compare aerosol effects over the WAM region and the Asian monsoon regions. 
A number of WAMME II studies were carried out using RCMs as well. De Sales et al. (2016) assess the impact of changes in vegetation condition and surface albedo over biomass-burned areas on the surface energy balance and WAM monthly evolution as simulated by a RCM. Wang et al. (2016) investigate LULCC impact on the WAM using a RCM with different lateral boundary conditions (LBC), one from reanalysis data for both control and LULCC simulations and another obtained from the corresponding control and LULCC GCM simulations, and compare the LBCs' influence on the simulated LULCC impact. In another RCM study (Druyan and Fulakeza 2016), the added value of downscaling atmosphere-ocean GCM simulations over Africa and adjacent oceans is examined.

This issue also has two papers that investigate the predictability and prediction issue. Otero et al. (2016) aim to assess the potential for decadal predictions with 14 models from the 5th Coupled Models Intercomparison Project (CMIP5) using a West African monsoon index (WAMI), based on low and high troposphere wind fields, and compare the results from WAMI with those from the precipitation-based indices. Mohino et al. (2016) propose a framework based on multilinear regression analysis to study the potential sources of skill for predicting Sahel trends, then apply it to extended decadal predictions performed with a climate model to identify major factors affecting the model's predictability.

Recent WAM numerical studies have highlighted the need for more analyses based on observational and assimilation data to improve model simulations and to understand the WAM physical processes. Due to the Saharan heat low's (SHL) pivotal role in the WAM, the recent trend in the SHL has been analyzed using two sets of reanalysis data and the simulation data from 15 atmospheric GCMs performed in the framework of the CMIP5 exercise (Lavaysse et al. 2016). Another study (Lélé and Leslie 2016) was based on reanalysis data and AMMA data to investigate the contribution of total low-level moisture flux and convergence due to mean circulation, as well as the synoptic and climate scale anomalies, and their relations with a dry and a wet year's precipitation. In addition, Kafando et al. (2016) employ the highresolution vertical profiles of temperature and horizontal wind data from the 2006 AMMA intensive field campaign to derive and analyze spectral characteristics of short-scale vertical waves over the West African lower stratosphere.

The papers in this special issue present the latest advances in WAM modeling and evaluation since the last special issue. This special issue reports the first attempt to specifically compare and assess the relative role and manifestations of different external forcings in WAM decadal variability. The findings from the papers in this issue will provide information that is not only useful for WAM research but also for societal applications (monitoring, water management, future projection, and possible mitigation activities). Some major weaknesses and challenges that still remain in the WAM modeling study have been identified. One key message emerging from WAMME II is that even with the combination of SST and land effects, a large fraction of WAM decadal variability remains unexplained. This means that other processes, such as aerosol, greenhouse gases, and internal variability, need to be included in a future synergized assessment of the relative roles of different processes in WAM variability at different scales.

In addition to the critical and useful comments provided by reviewers, Professor Edwin Schneider, the executive editor of Climate Dynamics, and other editors have made a great deal of effort in handling and helping this special issue. We appreciate their work for this special issue.

\section{References}

Boone A, Xue YK, De Sales F, Comer R, Hagos SM, Mahanama S, Schiro K, Song G, Wang G, Li S, Mechoso CR (2016) The regional impact of land-use land-cover change (LULCC) over West Africa from an ensemble of global climate models under the auspices of the WAMME2 project. Clim Dyn. doi:10.1007/ s00382-016-3252-y

De Sales F, Xue YK, Okin G (2016) Impact of burned area on the northern African seasonal climate from the perspective of regional modelling. Clim Dyn. doi:10.1007/s00382-015-2522-4

Druyan LM, Fulakeza M (2016) Downscaling GISS ModelE boreal summer climate over Africa. Clim Dyn. doi:10.1007/ s00382-015-2880-y

Gu Y, Xue YK, De Sales F, Liou KN (2016) A GCM investigation of dust aerosol impact on regional climate of North Africa and South/East Asia. Clim Dyn. doi:10.1007/s00382-015-2706-y

Kafando P, Chane-Ming F, Petitdidier M (2016) Stratospheric variability of wave activity and parameters in equatorial coastal and tropical sites during the West African Monsoon. Clim Dyn. doi:10.1007/s00382-015-2764-1

Lavaysse C, Flamant C, Evan A, Janicot S, Gaetani M (2016) Recent climatological trend of the Saharan heat Low and its impact on the West African climate. Clim Dyn. doi:10.1007/s00382-015-2847-z

Lélé MI, Leslie LM (2016) Intraseasonal variability of low-level moisture transport over West Africa. Clim Dyn. doi:10.1007/ s00382-016-3334-x

Mohino E, Keenlyside N, Pohlmann H (2016) Decadal prediction of Sahel rainfall: where does the skill (or lack of) come from? Clim Dyn. doi:10.1007/s00382-016-3416-9

Otero N, Mohino E, Gaetani M (2016) Decadal prediction of Sahel rainfall using dynamics-based indices. Clim Dyn. doi:10.1007/ s00382-015-2738-3

Wang G, Yu M, Xue YK (2016) Modeling the potential contribution of land use changes to the 20th. Clim Dyn. doi:10.1007/ s00382-015-2812-x

Xue YK, De Sales F, Lau WKM, Boone A, Kim KM, Mechoso CR, Wang G, Kucharski F, Schiro K, Hosaka M, Li S, Druyan LM, Seidou Sanda I, Thiaw W, Zeng N, Comer RE, Lim YK, Mahanama S, Song G, Gu Y, Hagos SM, Chin M, Schubert S, Dirmeyer P, Leung LR, Kalnay E, Kitoh A, Lu CH, Mahowald NM, Zhang Z (2016) West African monsoon decadal variability and drought and surface-related forcings: second West African monsoon modeling and evaluation project experiment (WAMME II). Clim Dyn. doi:10.1007/s00382-016-3224-2 